\title{
Total Hip and Knee Replacement in Eastern Libya: A Post-Conflict Case Series
}

\author{
Eman Elzwai ${ }^{1}$, Rasha Elhnid ${ }^{1}$, Zuhir Bodalal $^{2, *}$, Mustafa El Fadli ${ }^{1}$ and Salem Langhi ${ }^{1}$ \\ ${ }^{1}$ Department of Orthopedic Surgery, Benghazi Medical Center, Benghazi, Libya \\ ${ }^{2}$ Faculty of Medicine, Libyan International Medical University, Benghazi, Libya
}

\begin{abstract}
Background: Total knee replacement (TKR) and total hip replacement (THR) are effective procedures for alleviating pain and improving hip and knee function. Literature has not covered the experience of developing countries with arthroplasty - especially in an unstable post-conflict setting.

Methods: Patient records were obtained from a major surgical center in Benghazi where total joint arthroplasties (TJA) are performed for a period of twenty months and key parameters were analyzed. The patients were followed up on an outpatient basis at regular time intervals (one week, one month, three months and six months) and any complications were documented.

Results: A total of 135 total knee $(81.5 \%, n=110)$ and total hip $(18.5 \%, n=25)$ replacements were done in Benghazi mostly on elderly (mean age $=60.2$ years) females $(72.2 \%, n=100)$. The most common causative pathology in both groups was osteoarthritis $(80.6 \%, n=108)$. The most common complication was superficial infection $(4.4 \%, n=6)$ by Staph aureus. The Harris Hip Score and Knee Society Score were used to determine the functional outcomes of THR and TKR respectively - both showing high values. The Short form 36 (SF36) health survey was carried out to assess the patients' satisfaction levels. For all the axes, the obtained score was over $80 \%$.

Discussions: THR and TKR are major orthopedic surgeries that constitute an advancement in the treatment of chronic joint pain. Most of the demographic features of our patients match up well with previous literature - with certain exceptions. There was no difference in thromboembolic incidence between the group of patients who received LMWH and those who simply started early mobilization and physiotherapy. Despite a number of hindrances faced by the hospital due to the conflict (i.e. funding limitations and drug shortages), a low rate of complications was maintained. No thromboembolic incidents or mortalities occurred.

Conclusions: Libyan surgeons have had a good experience with TJA and patients have been satisfied with the outcomes.
\end{abstract}

Keywords: Total knee replacement, Total hip replacement, postoperative morbidity, Knee society score, Hip Harris score, SF36 health survey, Libya.

\section{INTRODUCTION}

Total knee replacement (TKR) and total hip replacement (THR) are effective procedures for relieving pain and poor physical functioning of both hip and knee joints [1]. Aging populations worldwide have greatly increased the rate of these arthroplasties and not just in the developed world.

The experience of developing countries in performing these major operations has not been covered in previous literature. Particular emphasis needs to be placed on the peculiarities in each country and the salient features of their patients in terms of outcome, satisfaction and prognosis.

Libya in particular would highlight a special case given the fact that it is current functioning in a postconflict settings. After the events of the 2011, the

*Address correspondence to these authors at the Department of Surgery, Faculty of Medicine, Libyan International Medical University, P.O. Box 15016, Benghazi, Libya; Tel: +218-91-478-9141; Fax: +218-61-223-3909;

E-mail: zuhir.bodalal@limu.edu.ly surgical services in general and the orthopedic hospitals in particular, have been facing the majority of trauma cases. Naturally, these cases have risen significantly in the past years [2-4]. Despite the increased load on these services, there have been hindrances that were faced and to an extent overcome by our staff in the form of medication/equipment shortages and funding limitations.

The main objective of this study is to present, for the first time, a case series for total hip and knee replacement surgery performed in Libya. The orthopedic community in Libya in general would gain knowledge of the circumstances faced by the orthopedic teams in Benghazi and the generally favourable outcomes relative to these conditions.

\section{METHODS}

Libya is a North African country located on the southern portion of the Mediterranean Sea. According to the 2006 Libyan census, the population in the eastern region of Libya exceeded 1.5 million 
inhabitants, one tenth of whom are above the age of 50 years [5].

This study was based in the Benghazi Medical Center (BMC) situated in Benghazi, Libya. Benghazi is the largest city in Libya and is home to over 800,000 people. The BMC is an important surgical center and hosts most of the major orthopedic operations (especially TKR and THR) performed in eastern Libya.
Data was gathered retrospectively utilizing patient records from the orthopedics department. The sample spanned the cases who were admitted during the 20month period between January 2012 till August 2013 and underwent either total hip or total knee replacement $(n=135)$. In our hospital, these two operations are carried out by two particular surgical teams; each of which spearheaded by a consultant

Table 1: A Comparative Analysis of Some Key Parameters between TKR and THR

\begin{tabular}{|c|c|c|c|c|}
\hline & \multicolumn{2}{|c|}{ Total Knee Replacement } & \multicolumn{2}{|c|}{ Total Hip Replacement } \\
\hline \multicolumn{5}{|l|}{ Gender ( $n \mid \%)$} \\
\hline Male & 25 & 22.7 & 10 & 40 \\
\hline Female & 85 & 77.3 & 15 & 60 \\
\hline Age (mean|SD) & \multicolumn{2}{|c|}{$64.4 \pm 6.6$ years } & \multicolumn{2}{|c|}{$42.1 \pm 9.9$ years } \\
\hline Duration of surgery (mean|SD) & \multicolumn{2}{|c|}{$120.1 \pm 48.8$ minutes } & \multicolumn{2}{|c|}{$104.6 \pm 45.7$ minutes } \\
\hline \multicolumn{5}{|l|}{ Primary causative condition ( $n \mid \%)$} \\
\hline Degenerative osteoarthritis & 99 & 90.2 & 12 & 48 \\
\hline Post-traumatic osteoarthritis & 5 & 4.9 & 6 & 24 \\
\hline Rheumatoid arthritis & 5 & 4.9 & - & - \\
\hline Avascular necrosis & - & - & 6 & 24 \\
\hline Others & - & - & 1 & 4 \\
\hline Total & 110 & 100 & 25 & 100 \\
\hline \multicolumn{5}{|l|}{ Affected joint (n|\%) } \\
\hline Right & 54 & 50.9 & 6 & 24 \\
\hline Left & 52 & 49.1 & 19 & 76 \\
\hline Total (excluding missing) & 106 & 100 & 25 & 100 \\
\hline Missing & 4 & - & - & - \\
\hline Total (including missing) & 110 & - & - & - \\
\hline \multicolumn{5}{|c|}{ American Society of Anesthesiologists classification (n|\%) } \\
\hline ASA1 & 66 & 60 & 17 & 68 \\
\hline ASA2 & 44 & 40 & 8 & 32 \\
\hline Total & 110 & 100 & 25 & 100 \\
\hline \multicolumn{5}{|l|}{ Type of anesthesia (n|\%) } \\
\hline Spinal & 60 & 57.1 & 4 & 19.1 \\
\hline General Anesthesia & 45 & 42.9 & 17 & 80.9 \\
\hline Total (excluding missing) & 105 & 100 & 21 & 100 \\
\hline Missing & 5 & - & 4 & - \\
\hline Total (including missing) & 110 & - & 25 & - \\
\hline \multicolumn{5}{|l|}{ Complications (n|\%) } \\
\hline No complications & 99 & 90 & 22 & 88 \\
\hline Anemia & 6 & 5.5 & 2 & 8 \\
\hline Superficial wound infection & 5 & 4.5 & 1 & 4 \\
\hline Total & 110 & 100 & 25 & 100 \\
\hline
\end{tabular}


orthopedic surgeon. All proper surgical techniques were followed during these operations.

Furthermore, the patients were followed up postoperatively by the two teams on an outpatient basis at various time intervals (one week, one month, three months and six months). As a means of assessing the results and satisfaction, patients underwent the Short Form-36 survey (as a measure of general health) and either the Harris Hip Score or Knee Society Score (as a measure of functional outcome) for THR or TKR patient respectively.

A number of parameters were recorded for each of the cases, among them; age, sex, type of procedure, duration of surgery, use of drains, length of hospital stay, type of anesthesia, ASA (American Society of Anesthesiologists) classification and use of preoperative prophylactic measure (particularly for infections, DVT and PE). An SPSS based model was designed and basic statistical procedures were carried out. The entire statistical workup was performed using SPSS (PASW) version 18.

The study was approved by the biomedical ethics committee at the Libyan International Medical University and was deemed to have complied with international ethical guidelines.

\section{RESULTS}

A total sample size of 135 patients underwent either $\operatorname{THR}(18.5 \%, \mathrm{n}=25)$ or $\operatorname{TKR}(81.5 \%, \mathrm{n}=110)$ at the BMC during the specified time period. The two different procedures were compared to each other for a variety of parameters (as shown in Table 1). THR patients on the whole were younger than their TKR counterparts $(p=0.116)$. In terms of gender distribution, females constituted the majority of patients for TKR $(77.3 \%$, $\mathrm{n}=85)$ and most of THR's were men $(42.9 \%, \mathrm{n}=15)$. While the most common causative condition was degenerative (primary) osteoarthritis $(80.6 \%, \mathrm{n}=108)$ other pathologies such as rheumatoid arthritis $(6.9 \%$, $n=9)$, post-traumatic (secondary) osteoarthritis $(8.3 \%$, $\mathrm{n}=11)$ and avascular necrosis $(6.9 \%, \mathrm{n}=9)$ also presented to the orthopedic ward. Hypertension was the most frequent comorbidity $(54 \%, n=73)$ seen in the TJA patients.

More patients underwent surgery on the left hip $(78.6 \%, n=106)$ than the right hip $(21.4 \%, n=29)$ $\left(x^{2}=4.571, p=0.03\right)$, such a difference did not exist for knee replacement $\left(x^{2}=0.071, p=0.789\right)$.
The outcome was measured objectively for the hip replacement group using the Harris Hip Score and the Knee Society Score was the scale used for knee replacement patients - a higher score indicates a better functional outcome. These scores are depicted graphically in Figures 1 and $\mathbf{2}$.

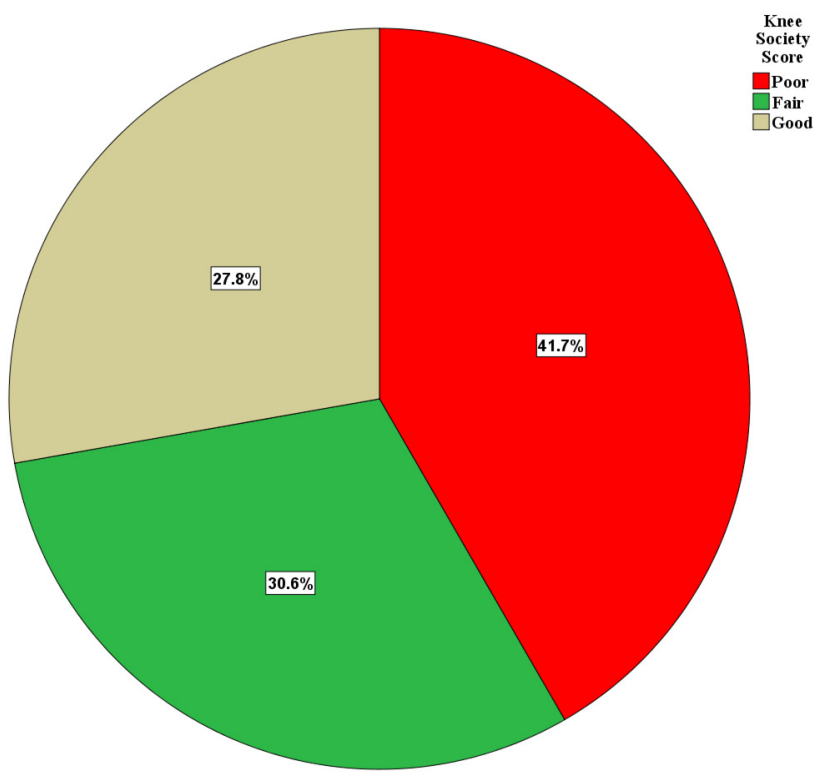

Figure 1: The marks obtained by the TKR patients according the Knee Society Score.

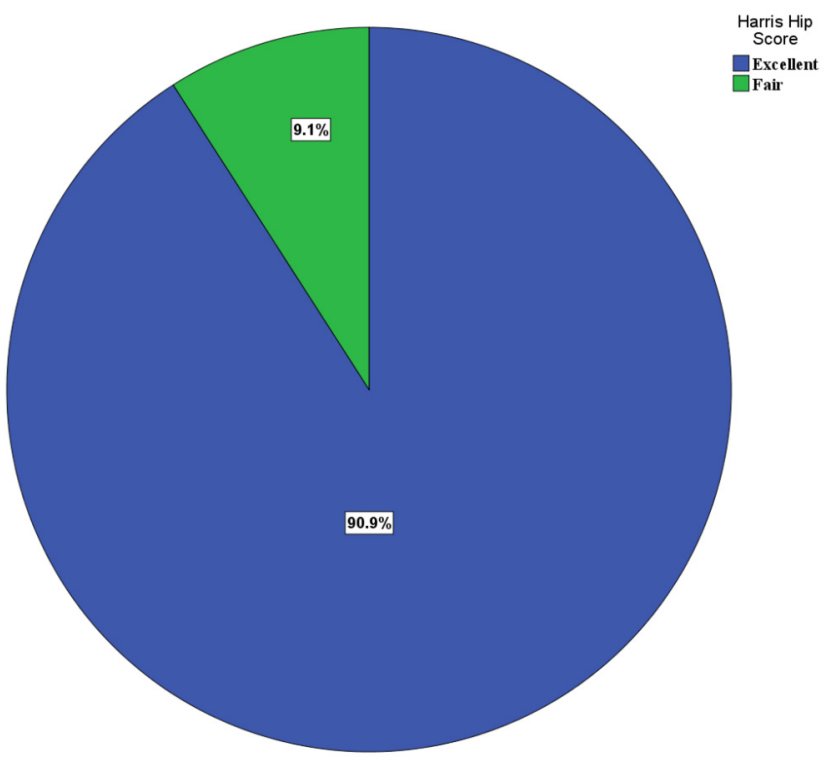

Figure 2: The marks obtained by the THR patients according the Harris Hip Score.

As a prophylactic measure, an antibiotic (ceftriaxone) was administered both intraoperatively and 24 hours postoperatively. The patients were followed up on an outpatient basis across different period of time (one week, one month, three months and 
six months) and only $4.4 \%(n=6)$ were found to have infections. All of which were superficial and successfully managed with antibiotics. Two patients received oral broad spectrum antibiotics and received dressing in the outpatient clinic while four other patients had to be admitted to the hospital and ultimately received intravenous antibiotics as per the culture and sensitivity results. Swabs taken from patients' wounds admitted to the hospital were positive for Staphylococcus aureus. One patient had methicillinresistant Staphylococcus aureus (MRSA) and they were promptly placed in a single isolated room and treated successfully with vancomycin.

The two teams performing the joint replacement surgeries took alternate approaches to thromboembolic prophylaxis; one chose low molecular weight heparin $(\mathrm{LMWH})$ throughout the patient's stay while the other team opted for early mobilization. No significant difference was found between them in terms, especially since none of the patients suffered from either DVT or PE.

Most of the patients in the THR group were mainly in the ASA1 $(70 \%, n=17)$ category while those scheduled for TKR were ASA2 $(60 \%, n=66)$. The commonest type of anesthesia used was spinal anesthesia and sedation $(48.6 \%, \mathrm{n}=65)$. The average duration of surgery was $120 \mathrm{~min}$, ranging from 35 minutes up to 225 minutes. Non-cemented cups and stems were used for patients and closed suction drains were used in all the cases.

The patients were transferred postoperatively to the orthopedic ward and started physiotherapy the next day. This consisted of continuous passive motion (CPM), mobilization, and full weight bearing. The mean length of stay in hospital was 7 days (see Figure 3).

The average of hemoglobin in TKR was $9.8 \mathrm{mg} / \mathrm{dl}$ and in THR it was $14.3 \mathrm{mg} / \mathrm{dl}$. Patients were discharged on oral tonic and high iron and protein diet.

No significant association was seen between the existence of a comorbidity and the complication rate in either TKR $(p=0.196)$ or THR $(p=0.118)$.

The knee society score was used to evaluate the functional outcome of patients who underwent total knee replacement and the score is a composite of values given for range of motion, stability, and alignment (0-50 points).

The Short form 36 (SF36) health survey (comprising 36 questions) was carried out to assess the patients'

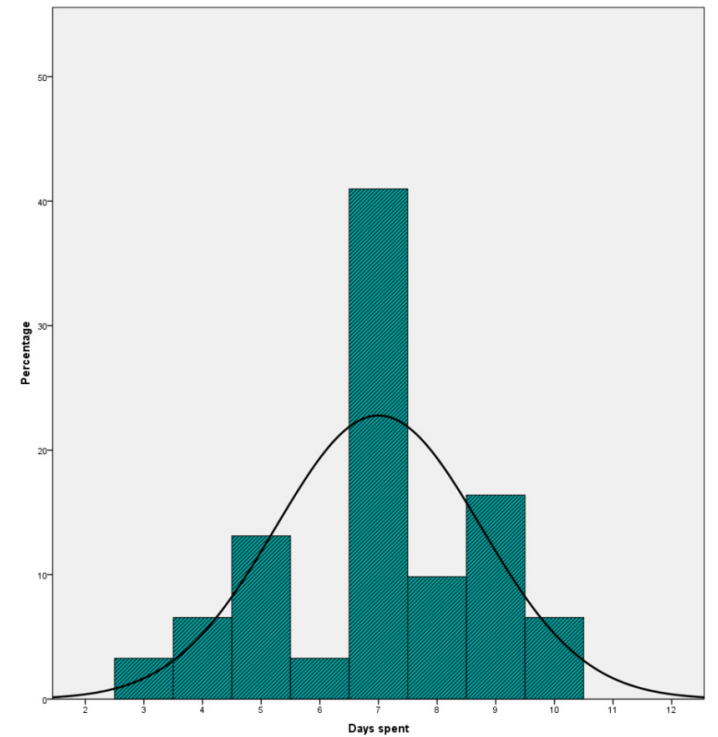

Figure 3: The distribution of patients according their length of stay in the hospital.

general health level and physical and social functioning (see Figures 4 and 5). For all the axes, the obtained score was over $80 \%$ - the lowest being in physical function $(80 \%)$ and the highest being general health mean $(95 \%)$.

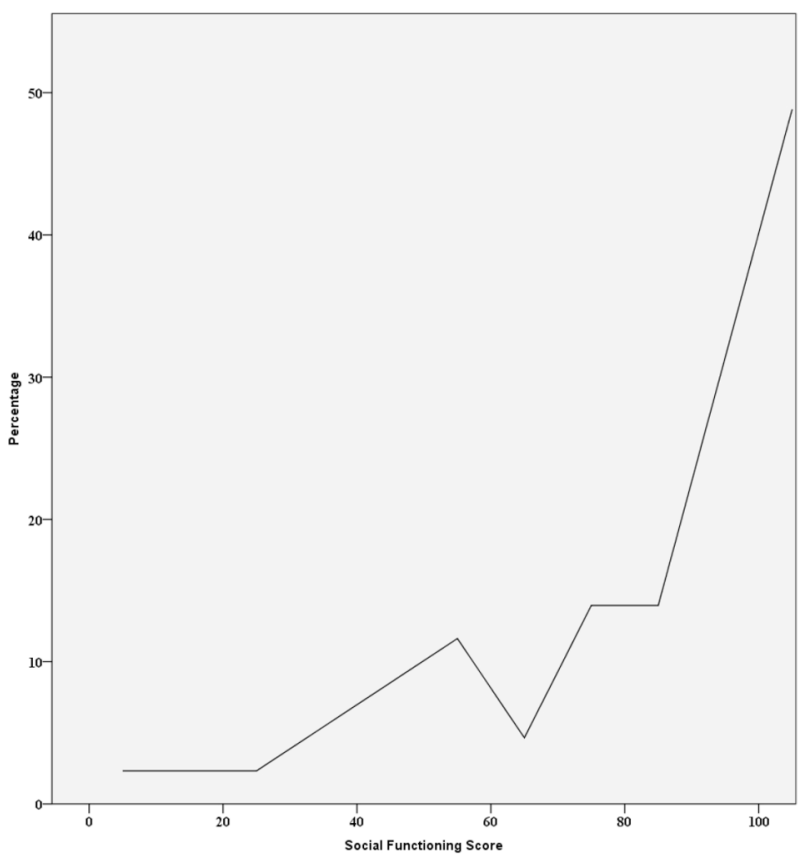

Figure 4: The results obtained by the patients according the Short Form-36 for both physical functioning.

\section{DISCUSSION}

Total knee and hip replacement surgeries constitute a major advancement in the treatment of chronic joint pain. It is indicated in patients for whom conservative 


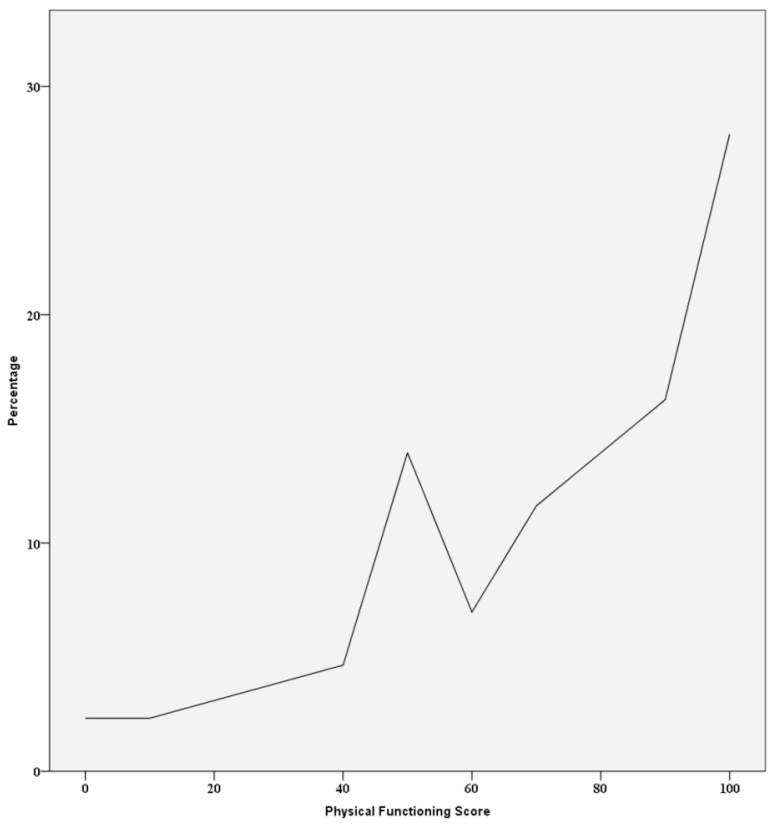

Figure 5: The results obtained by the patients according the Short Form-36 for both physical and social functioning.

medical therapy has failed. In addition to the alleviation of pain, there is a marked improvement in function and quality of life in patients with knee and hip disorders [1].

The bulk of our patients were elderly females suffering from osteoarthritis. Demographically, this correlated well with previous literature [6-8]. The only exception was a study produced by Lenza et al. which reported a higher operative rate for males [6].

Osteoarthritis (OA) was by far the most common causative pathology for both TKR and THR. While the risk factors for knee OA have been well documented in literature (particularly obesity, gender predilection and functional/occupational aspects [9]), the same cannot be said for hip OA [10, 11]. Jacobsen et al. reported increased age and hip dysplasia as risk factors for hip $\mathrm{OA}$ in women and only the latter in men [12].

Our joint replacement patients are younger on average than reported values. This is particular true for hip replacement $[6,7,13,14]$. Spinal anesthesia and sedation was the most common type of anesthesia used with the majority of patients staying around a week. While this corroborates with previous figures $[6$, 15-17], a contradictory result [18] is that there was no association between any of the parameters studied and length of stay.

There was no difference in thromboembolic incidence between the group of patients who received LMWH and those who simply started early mobilization and physiotherapy. Early postoperative mobilization has been shown to reduce the risk of venous thromboembolism [17, 19]. Others have stated that continuous passive movement does not conclusively prevent DVT after TKR [20]. No mortalities were observed in our experience with joint replacement surgery.

Anemia is common in patients undergoing total joint arthroplasty where numerous studies have associated with prolonged hospital stays and greater infection/mortality risks [21]. In our practice, any patient with a hemoglobin level below $8.5 \mathrm{~g} / \mathrm{dl}$ was given a blood transfusion and was provided with a prescription an oral tonic as well as a high protein/iron diet.

The infection rate reported in our study is higher than most previous reported values (ranging from $1 \%$ to $2.6 \%)[7,14,22]$, however there were figures that exceed our own (such as in the Norwegian experience [23]). None of our cases required a second surgery or suffered a complication (i.e. fracture dislocations). No association was found between the rate of complications and the presence of a comorbidity [7].

Physiotherapy is pivotal to the patient's recovery after either THR or TKR [24]. Recovery is hastened with the inclusion of physiotherapy programs that are needed to restore mobility and independence [25]. The main outcomes that patients expect from physiotherapy are pain relief and improved walking ability [26-29]. In fact, it has been shown that patients are often more interested in alleviating the pain than regaining function [30, 31]. Women have even been reported to undergo TKA to be able to resume their care-giving tasks within the family [9].

While a great variety can exist in recovery time following a total joint arthroplasty, substantial gains are made between the 3-6 postoperatively $[32,33]$ and there is a continuing pattern of improvement up to a year after the surgery [34, 35].

Risk factors which impact patient outcomes after TKR include age and gender [36-38], causative pathology [39], body mass index [40, 41], psychological distress [39, 42], baseline pain and functional disability $[39,43]$, comorbidity profile [44], socioeconomic status [45], and radiographic osteoarthritis severity [36, 43]. Obesity and psychological distress are modifiable risk factors [46] and as such determining the exact causal relationship between the various factors and the outcome would prove invaluable. 
Pain relief was superior in THR than TKR both quantitatively and qualitatively [47]. Additionally, the replaced hips showed greater functional outcomes which might be due to the fact that a ball and socket joint (i.e. the hip) is easier to mimic artificially than a hinge joint (i.e. the knee) [48]. Another factor that might have also assisted this finding in our study was the relative youth of the THR subgroup. came earlier and was greater for THR than for

\section{CONFLICT OF INTEREST STATEMENT}

The authors declare that there is no conflict of interest whatsoever and that no funding was received during this study.

\section{ACKNOWLEDGEMENTS}

The authors would like to extend their gratitude to all the staff at the Benghazi Medical Center (BMC) for their assistance during data gathering and analysis.

\section{REFERENCES}

[1] Singh JA. Epidemiology of knee and hip arthroplasty: a systematic review. Open Orthop J 2011; 5: 80-85. http://dx.doi.org/10.2174/1874325001105010080

[2] Bodalal Z, Mansor S. Gunshot injuries in Benghazi-Libya in 2011: The Libyan conflict and beyond. Surgeon 2013; 11: 258-263.

http://dx.doi.org/10.1016/j.surge.2013.05.004

[3] Bodalal Z, Bendardaf R, Ambarek M, Nagelkerke N. Road traffic accidents in Benghazi during the Libyan conflict: the impact of absent law enforcement. Ibnosina Journal of Medicine and Basic Sciences Submitted and under review.

Bodalal Z, Bendardaf R, Ambarek M. A study of a decade of road traffic accidents in Benghazi-Libya: 2001 to 2010. PLoS One 2012; 7: e40454.

http://dx.doi.org/10.1371/journal.pone.0040454

[5] Libyan Census: 2006. In. Tripoli, Libya: Libyan Department of Documentation 2006.

[6] Lenza M, Ferraz Sde B, Viola DC et al. Epidemiology of total hip and knee replacement: a cross-sectional study. Einstein (Sao Paulo) 2013; 11: 197-202. http://dx.doi.org/10.1590/S1679-45082013000200011

[7] Liu YE, Hu S, Chan SP, Sathappan SS. The epidemiology and surgical outcomes of patients undergoing primary total hip replacement: an Asian perspective. Singapore Med J 2009; 50: 15-19.

[8] Kim HA, Kim S, Seo YI et al. The epidemiology of total knee replacement in South Korea: national registry data. Rheumatology (Oxford) 2008; 47: 88-91. http://dx.doi.org/10.1093/rheumatology/kem308

[9] Al-Taiar A, Al-Sabah R, Elsalawy E et al. Attitudes to knee osteoarthritis and total knee replacement in Arab women: a qualitative study. BMC Res Notes 2013; 6: 406. http://dx.doi.org/10.1186/1756-0500-6-406

[10] Axmacher B, Lindberg $H$. Coxarthrosis in farmers. Clin Orthop Relat Res 1993; 82-86.

[11] Coggon D, Croft P, Kellingray $S$ et al. Occupational physical activities and osteoarthritis of the knee. Arthritis Rheum 2000; 43: 1443-1449 http://dx.doi.org/10.1002/1529-0131(200007)43:7<1443::AIDANR5>3.0.CO;2-1
Jacobsen S, Sonne-Holm S. Increased body mass index is a predisposition for treatment by total hip replacement. Int Orthop 2005; 29: 229-234. http://dx.doi.org/10.1007/s00264-005-0658-2

[13] Total knee replacement: an evidence-based analysis. Ont Health Technol Assess Ser 2005; 5: 1-51.

[14] Ng CY, Ballantyne JA, Brenkel IJ. Quality of life and functional outcome after primary total hip replacement. A five-year follow-up. J Bone Joint Surg Br 2007; 89: 868-873. http://dx.doi.org/10.1302/0301-620X.89B7.18482

[15] Wood A, Keenan A, Arthur C et al. The functional outcome of total knee replacement in young patients: A 10-year matched case control study. Open Journal of Orthopedics 2013; 3: 128-132.

http://dx.doi.org/10.4236/ojo.2013.32024

[16] Muniz-Terrera G, van den Hout A, Piccinin AM et al. Investigating terminal decline: results from a UK populationbased study of aging. Psychol Aging 2013; 28: 377-385. http://dx.doi.org/10.1037/a0031000

[17] Raut S, Mertes SC, Muniz-Terrera G, Khanduja V. Factors associated with prolonged length of stay following a total knee replacement in patients aged over 75. Int Orthop 2012; 36: 1601-1608.

http://dx.doi.org/10.1007/s00264-012-1538-1

[18] Jonas SC, Smith HK, Blair PS et al. Factors influencing length of stay following primary total knee replacement in a UK specialist orthopaedic centre. Knee 2013; 20: 310-315. http://dx.doi.org/10.1016/i.knee.2012.07.010

[19] Chandrasekaran S, Ariaretnam SK, Tsung J, Dickison D. Early mobilization after total knee replacement reduces the incidence of deep venous thrombosis. ANZ J Surg 2009; 79: 526-529.

http://dx.doi.org/10.1111/j.1445-2197.2009.04982.x

[20] He ML, Xiao ZM, Lei $M$ et al. Continuous passive motion for preventing venous thromboembolism after total knee arthroplasty. Cochrane Database Syst Rev 2012; 1: CD008207.

[21] Greenky M, Gandhi K, Pulido L et al. Preoperative anemia in total joint arthroplasty: is it associated with periprosthetic joint infection? Clin Orthop Relat Res 2012; 470: 2695-2701. http://dx.doi.org/10.1007/s11999-012-2435-z

[22] Blom AW, Taylor AH, Pattison G et al. Infection after total hip arthroplasty. The Avon experience. J Bone Joint Surg $\mathrm{Br}$ 2003; 85: 956-959.

http://dx.doi.org/10.1302/0301-620X.85B7.14095

[23] Dale H, Skramm I, Lower HL et al. Infection after primary hip arthroplasty: a comparison of 3 Norwegian health registers. Acta Orthop 2011; 82: 646-654

http://dx.doi.org/10.3109/17453674.2011.636671

[24] Minns Lowe CJ, Barker KL, Dewey ME, Sackley CM. Effectiveness of physiotherapy exercise following hip arthroplasty for osteoarthritis: a systematic review of clinical trials. BMC Musculoskelet Disord 2009; 10: 98.

http://dx.doi.org/10.1186/1471-2474-10-98

[25] Jones CA, Beaupre LA, Johnston DW, Suarez-Almazor ME. Total joint arthroplasties: current concepts of patient outcomes after surgery. Clin Geriatr Med 2005; 21: 527-541, vi. http://dx.doi.org/10.1016/j.cger.2005.02.005

[26] Mancuso CA, Salvati EA, Johanson NA et al. Patients expectations and satisfaction with total hip arthroplasty. J Arthroplasty 1997; 12: 387-396. http://dx.doi.org/10.1016/S0883-5403(97)90194-7

[27] Mancuso CA, Jout J, Salvati EA, Sculco TP. Fulfillment of patients' expectations for total hip arthroplasty. J Bone Joint Surg Am 2009; 91: 2073-2078 http://dx.doi.org/10.2106/JBJS.H.01802

[28] Ghomrawi HM, Franco Ferrando N, Mandl LA et al. How Often are Patient and Surgeon Recovery Expectations for 
Total Joint Arthroplasty Aligned? Results of a Pilot Study. HSS J 2011; 7: 229-234.

http://dx.doi.org/10.1007/s11420-011-9203-6

[29] Wylde V, Blom AW, Whitehouse SL et al. Patient-reported outcomes after total hip and knee arthroplasty: comparison of midterm results. J Arthroplasty 2009; 24: 210-216. http://dx.doi.org/10.1016/j.arth.2007.12.001

[30] Jones CA, Voaklander DC, Johnston DW, Suarez-Almazor ME. Health related quality of life outcomes after total hip and knee arthroplasties in a community based population. J Rheumatol 2000; 27: 1745-1752.

[31] Jones CA, Voaklander DC, Johnston DW, Suarez-Almazor ME. The effect of age on pain, function, and quality of life after total hip and knee arthroplasty. Arch Intern Med 2001; 161: 454-460. http://dx.doi.org/10.1001/archinte.161.3.454

[32] Shields RK, Enloe LJ, Leo KC. Health related quality of life in patients with total hip or knee replacement. Arch Phys Med Rehabil 1999; 80: 572-579. http://dx.doi.org/10.1016/S0003-9993(99)90202-2

[33] Rissanen P, Aro S, Sintonen $\mathrm{H}$ et al. Quality of life and functional ability in hip and knee replacements: a prospective study. Qual Life Res 1996; 5: 56-64. http://dx.doi.org/10.1007/BF00435969

[34] Huang NF, Dowsey MM, Ee E et al. Coronal alignment correlates with outcome after total knee arthroplasty: fiveyear follow-up of a randomized controlled trial. J Arthroplasty 2012; 27: 1737-1741. http://dx.doi.org/10.1016/j.arth.2012.03.058

[35] Nilsdotter AK, Toksvig-Larsen S, Roos EM. A 5 year prospective study of patient-relevant outcomes after total knee replacement. Osteoarthritis Cartilage 2009; 17: 601606.

http://dx.doi.org/10.1016/j.joca.2008.11.007

[36] Dowsey MM, Dieppe P, Lohmander S et al. The association between radiographic severity and pre-operative function in patients undergoing primary knee replacement for osteoarthritis. Knee 2012; 19: 860-865.

http://dx.doi.org/10.1016/j.knee.2012.02.007

[37] Williams DP, Price AJ, Beard DJ et al. The effects of age on patient-reported outcome measures in total knee replacements. Bone Joint J 2013; 95-B: 38-44. http://dx.doi.org/10.1302/0301-620X.95B1.28061

[38] Liu SS, Buvanendran A, Rathmell JP et al. A cross-sectional survey on prevalence and risk factors for persistent postsurgical pain 1 year after total hip and knee replacement. Reg Anesth Pain Med 2012; 37: 415-422.

http://dx.doi.org/10.1097/AAP.0b013e318251b688

[39] Judge A, Arden NK, Cooper C et al. Predictors of outcomes of total knee replacement surgery. Rheumatology (Oxford) 2012; 51: 1804-1813.

http://dx.doi.org/10.1093/rheumatology/kes075

[40] Dowsey MM, Liew D, Stoney JD, Choong PF. The impact of pre-operative obesity on weight change and outcome in total knee replacement: a prospective study of 529 consecutive patients. J Bone Joint Surg Br 2010; 92: 513-520. http://dx.doi.org/10.1302/0301-620X.92B4.23174

[41] McElroy MJ, Pivec R, Issa K et al. The effects of obesity and morbid obesity on outcomes in TKA. J Knee Surg 2013; 26: 83-88. http://dx.doi.org/10.1055/s-0033-1341407

[42] Paulsen MG, Dowsey MM, Castle D, Choong PF. Preoperative psychological distress and functional outcome after knee replacement. ANZ J Surg 2011; 81: 681-687. http://dx.doi.org/10.1111/j.1445-2197.2010.05634.x

[43] Dowsey MM, Nikpour M, Dieppe P, Choong PF. Associations between pre-operative radiographic changes and outcomes after total knee joint replacement for osteoarthritis. Osteoarthritis Cartilage 2012; 20: 1095-1102. http://dx.doi.org/10.1016/j.joca.2012.05.015

[44] Hawker GA, Badley EM, Borkhoff CM et al. Which patients are most likely to benefit from total joint arthroplasty? Arthritis Rheum 2013; 65: 1243-1252. http://dx.doi.org/10.1002/art.37901

[45] Clement ND, Jenkins PJ, MacDonald D et al. Socioeconomic status affects the Oxford knee score and short-form 12 score following total knee replacement. Bone Joint J 2013; 95-B: 52-58.

http://dx.doi.org/10.1302/0301-620X.95B1.29749

[46] Dowsey MM, Choong PF. The utility of outcome measures in total knee replacement surgery. Int J Rheumatol 2013; 2013: 506518.

[47] Mainard D, Guillemin F, Cuny C et al. [Quality of life assessment one year after total hip or knee arthroplasty]. Rev Chir Orthop Reparatrice Appar Mot 2000; 86: 464-473.

[48] Mahomed N, Gandhi R, Daltroy L, Katz JN. The selfadministered patient satisfaction scale for primary hip and knee arthroplasty. Arthritis 2011; 2011: 591253. http://dx.doi.org/10.1155/2011/591253 